\title{
The Costs of
}

\section{Benzodiazepine-Associated Hospital-Treated Fall Injuries in the EU: A Pharmo Study}

\author{
Martien J.M. Panneman, ${ }^{1}$ Wim G. Goettsch, ${ }^{1}$ Piotr Kramarz ${ }^{2}$ and \\ Ron M.C. Herings ${ }^{1,3}$ \\ 1 Pharmo Institute, Utrecht, The Netherlands \\ 2 Pfizer International, Warsaw, Poland \\ 3 Department of Pharmaco-epidemiology and Pharmacotherapy, Utrecht Institute for \\ Pharmaceutical Sciences, Utrecht University, Utrecht, The Netherlands
}

\section{Abstract}

Objective: To estimate the hospitalisation costs of accidental fall injuries in the EU resulting from the use of benzodiazepines.

Methods: Risk and exposure data were obtained from the Dutch Pharmo system, a population-based register of drug-dispensing records and hospital records. The population attributable risk (PAR) was calculated using the age-specific prevalence estimates of benzodiazepine use and the corresponding relative risk (RR), obtained from a case-control study in community-dwelling inhabitants over 55 years of age in defined areas of The Netherlands covering the period 1985-2000. Annual hospitalisation costs of benzodiazepine-related fall injuries were based on the age-specific PARs and extrapolated to the European population using accident and demographic data of the EU. All analyses were performed from the perspective of a third-party payer.

Results: Fall injuries in the study population were significantly associated with benzodiazepine use (RR 1.6, 95\% CI 1.4-1.7), especially in those aged over 85 years (RR 3.6, 95\% CI 2.9-4.5). The total annual hospital direct medical costs in 2000 of fall-related injuries attributable to benzodiazepine use were $€ 1.8$ billion (95\% CI $€ 1.5-2.2$ billion) in the EU.

Conclusions: The estimated costs of hospitalisations of accidental-fall injuries related to benzodiazepine use in the EU varied between $€ 1.5$ and $€ 2.2$ billion each year. More than $90 \%$ of these costs were in the elderly, with hip fractures as the major contributor. Discontinuing benzodiazepines in the elderly and/or substituting them with other drugs not associated with the risk of falls in the elderly will to a large extent prevent these accidents.
Benzodiazepines are among the most widely prescribed drugs in the western world for the treatment of anxiety and sleep disorders. Use of benzodiazepines has been consistently reported as an indepen- 
dent risk factor for accidental falls, particularly in the elderly. ${ }^{[1]}$ Data from several reviews indicate more than 40 studies have described increased risks of accidental falls with the use of benzodiazepines, ranging from 1.4-1.8. ${ }^{[1-3]}$ Because of the widespread use of benzodiazepines, it can be assumed that use of these drugs may have significant economic consequences. Herings et al. estimated in 1995 that approximately $10 \%$ of the total treatment costs of hip fractures, mostly resulting from accidental falls, could be attributed to benzodiazepine use in The Netherlands. ${ }^{[1]}$

Approximately $80 \%$ of fall-related injuries in those aged over 50 years result in osteoporotic fractures. ${ }^{[1]}$ Various estimates and projections have been made on the burden of osteoporotic fractures in some European countries, the US and worldwide. Annual costs are estimated to be between \$US7-20 billion in the US (1994 costs) and about $€ 1.1$ billion in the UK (1995-1996 costs), including all in- and outpatient costs; $60 \%$ of these costs are attributable to hip fractures. ${ }^{[4-6]}$ Worldwide projections on annual hip fracture-related costs approximate $€ 50$ billion in 2002 and exceed $€ 130$ billion in 2050, as the population ages. ${ }^{[7]}$ In smaller European countries, such as Austria and Belgium, the annual hospital inpatient costs of hip fractures were assessed, respectively, at $€ 103$ (1995 costs) and $€ 118$ million (1996 costs). ${ }^{[8,9]}$

The main purpose of this study was to estimate the burden of benzodiazepine-associated hospitalisations because of accidental injuries (falls only) in The Netherlands and the EU, using the population attributable risk multiplied by treatment costs (PARC) as described by Herings and Klungel. ${ }^{[10]}$

\section{Methods}

\section{Study Design}

The method applied to estimate the burden of benzodiazepine-associated accidental fall injuries was based on the PARC. ${ }^{[10]}$ The PARC represents an estimate of the proportion of fall-related injury treatment costs that may be attributed to benzodiazepine use. It is a function of the age and gender-specific prevalence of benzodiazepine use, the relative risk (RR) of falling resulting in injury whilst taking benzodiazepines and the year-specific treatment costs for all fall-related injuries.

\section{Population Attributive Risk}

The population attributable risk (PAR) is estimated per age (5-year classes) $(i)$ and gender $(j)$ and represents the proportion of the outcome (accidents) that is directly attributable to the studied exposure (benzodiazepines), expressed as (equation 1):

$$
\mathrm{PAR}_{i j}=p_{i j} \times\left(\mathrm{RR}_{i j}-1\right) /\left\{p_{i j} \times\left(\mathrm{RR}_{i j}-1\right)+1\right\}
$$

where pij is the prevalence of exposure to which the RR (RRij) refers for each age and gender group. ${ }^{[11]}$

Benzodiazepine-attributable costs (PARCs) were obtained by multiplying PARs by costs of hospitalisation using the following equation (equation 2):

$$
\mathrm{AI}_{\mathrm{NL}}=\Sigma\left(\mathrm{PAR} \times \text { Cost }_{\text {Hospitalisation }}\right)_{\text {age-gender }}
$$

By summating PARCs, a weighted estimate was obtained for the total benzodiazepine-related hospitalisation costs of fall-related accidental injuries ( $\mathrm{AI}_{\mathrm{NL}}$ ) in The Netherlands after standardisation to the Dutch population (January 1st 2001).

\section{Data Sources}

Data for this study were obtained from the Pharmo medical record linkage system in The Netherlands. The Pharmo medical record linkage system includes the drug-dispensing records from community pharmacies and hospital discharge records of 1 million residents of 24 geographical areas scattered throughout The Netherlands. For all residents, the drug-dispensing histories of community pharmacies are linked to the hospital discharge records of the same patient, using a probabilistic algorithm, based on characteristics such as date of birth, gender and a code for the general practitioner. Validation of 9822 linked records showed that these registries were linked with a sensitivity and specificity exceeding 95\%. ${ }^{[12]}$ The computerised drug-dispensing histories contain data concerning the dispensed drug, type of prescriber, dispensing date, dispensed amount, dosage regimens and the prescription duration. The hospital records include 
detailed information concerning the primary and secondary diagnoses, procedures and dates of hospital admission and discharge. All diagnoses were coded according to the International Classification of Diseases, 9th Revision, Clinical Modification. Accident-related admissions were encoded with 'E'codes as secondary diagnoses, validated in 2001. ${ }^{[13]}$ Drugs were coded according to the Anatomical Therapeutic Chemical classification.

\section{Prevalence and Relative Risk}

The prevalence of benzodiazepine use was measured as the percentage of users on a single day in the year 2000 (first Wednesday in October) among all people aged 55 years or more registered in the Pharmo database. ${ }^{[14]}$ Exposure to benzodiazepines was ascertained from computerised records of prescriptions filled at community pharmacies. For each prescription of a benzodiazepine, the duration of the treatment was calculated by dividing the number of dispensed tablets by the prescribed daily dose.

A case-control study was performed in the Pharmo system to estimate the relationship between accidental falls and use of benzodiazepines. Cases were defined as community dwelling patients treated in hospital with an accidental fall as a major cause of injury (based on 'E'-codes: E880-E888) and with a primary diagnosis of: fractures (800-829); luxations, distorsions, intracranial and internal injuries or open wounds (830-897); and grazes and contusions (910-924) between January 1985 and December 2000. Each case had at least 6 months of dispensing data in the Pharmo system before hospital admission. For each case, the index date was defined as the date of hospital admission for an accidental fall.

All possible cases and controls from the Pharmo database were selected. There were 9081 cases historically matched to 9081 controls. Controls were matched to cases on index day, year of birth, gender and pharmacy. Controls without a dispensing of any drug before and after the index date, with an accidental fall-related hospitalisation in the preceding year, or a transfer to another hospital were excluded from the study.

\section{Hospitalisation Costs of Fall-Related Injuries in Europe}

For each admission that complied with the inclusion criteria for this study, the costs of the hospital charges, i.e. admission day cost, the costs of procedures, fee of medical specialists and costs of tests, were calculated per patient and per hospital. These costs are the best estimates for the actual costs charged by third-party payers. ${ }^{[10]}$ Total costs were obtained by summating all PARCs per age class (5-year classes) and gender in the Pharmo area. Total cost estimates were obtained for The Netherlands by direct reference to the Dutch population at January $1^{\text {st }}$ which was assumed to be the standard population. The Dutch age-specific admission figures and costs were extrapolated to the EU. Adjustments for local variations in age distribution, fracture incidence and health expenses were made using the demographic figures of each country (Eurostat, Luxembourg) and the indices based on hip fracture-related discharge rates (IFRD) and inpatient expenses per bed-day (IEBD) for each EU member state ${ }^{[10,15,16]}$ (table I). The adjusted fracture incidences were multiplied by the obtained admission costs and summated to obtain the total treatment costs for each country and age category over 55 years according to the following formula:

Table I. Indices for hip fracture discharge rates and daily in-patient expenses per capita for each EU member state

\begin{tabular}{lll}
\hline EU country & $\begin{array}{l}\text { Index for hip fracture } \\
\text { related discharge }\end{array}$ & $\begin{array}{l}\text { Index for expenditure } \\
\text { per bed day }\end{array}$ \\
\hline Austria & 1.65 & 0.97 \\
Belgium & 1.34 & 1.04 \\
Denmark & 1.24 & 3.21 \\
Finland & 2.22 & 0.71 \\
France & 0.78 & 1.35 \\
Germany & 1.21 & 1.09 \\
Greece & 0.81 & 0.57 \\
Ireland & 1.00 & 0.73 \\
Italy & 1.20 & 1.53 \\
Luxembourg & 1.25 & 0.79 \\
Netherlands & 1.00 & 1.00 \\
Portugal & 0.87 & 0.79 \\
Spain & 0.75 & 1.36 \\
Sweden & 2.62 & 0.99 \\
UK & 1.00 & 0.75 \\
\hline
\end{tabular}


CostEU $U_{\text {age }}=\left(\right.$ PrevNL $L_{\text {age }} /$ DenomNL age $) \times$ DenomEU $U_{\text {age }} \times$ IFRD $\times$ MCostNLage $\times$ IEBD

where CostEU $U_{\text {age }}$ is the total costs of fall-related hospitalisations per age-group in an EU country, DenomEU $U_{\text {age }}$ is the population denominator per age group in an EU country, DenomNLage is the population denominator per age group in The Netherlands, MCostNLage is the mean cost of a fall-related admission per age group in The Netherlands, and PrevNL $L_{\text {age }}$ is the prevalence of falls in The Netherlands per age group (number of falls/population).

Finally, the benzodiazepine-related contribution to the expenses of accidental falls in Europe was calculated by multiplying the total European sum of admission costs by the age-specific PARs and then summating to reach an overall cost.

\section{Statistical Analyses}

Conditional logistic regression analyses were performed to estimate the RR of an accidental fallrelated hospitalisation associated with the use of benzodiazepines by using SAS v8.2 (SAS Institute, Cary, NC, USA). ${ }^{[17]}$ Potential confounders that could be assessed by using pharmacy and hospitalisation data included Parkinson's disease and the use of antidepressants. ${ }^{[1]}$ Other confounders were ignored as they had no effect on the benzodiazepinerelated RRs. Confidence intervals $(95 \%)$ for the PAR were derived from the lower and upper confidence limits of the RR. Because of the large number of benzodiazepine users, the error in the prevalence estimates was small and therefore neglected. RRs and corresponding confidence intervals were calculated for each age and gender group.

\section{Results}

\section{Use of Benzodiazepines}

In The Netherlands, the total number of benzodiazepine prescriptions was 12.4 million in the year 2000 (table II). Benzodiazepines were most frequently labelled for the treatment of anxiety (>55\%). In 2000, 13510 patients of the Pharmo population and 675000 inhabitants of The Nether- lands were continuous users of one or more benzodiazepines. More than $15 \%$ of these patients used several different benzodiazepines concurrently. Among the continuous users, women were in the majority: 473000 women versus 202000 men. About $47 \%$ of the continuous users were more than 65 years old, while this age group only represented $13.6 \%$ of the Dutch population.

\section{Benzodiazepine Related-Fall Injuries}

1478 study participants and 1019 matched controls were taking benzodiazepines at the time of the fall accident. The overall age- and gender-adjusted $\mathrm{RR}$ associated with benzodiazepine use was 1.6 (95\% CI 1.4-1.7). This risk increased with age from a moderate risk among people younger than 45 years (RR 1.4, 95\% CI 1.0-2.0) to a 3.6-fold risk in subjects aged 85 years and older (95\% CI 2.9-4.5). A slightly increased risk was found in females compared with males.

\section{Population Attributive Risk}

In figure 1, PARs for benzodiazepine fall-related injuries for men and women in the EU are presented based on data from the study population on the agespecific prevalence of use of benzodiazepines (table III) and the RR of benzodiazepine fall-related injuries (table IV). Among users $<75$ years of age, the PAR ranged between $0.7-8.4 \%$. The PAR increased, however, from $10.4 \%$ in users aged $75-79$ years to $41.6 \%$ in users aged 85 years and older. Benzodiazepine-induced fall accidents were higher in women than in men.

Table II. Benzodiazepine use in the Pharmo area, The Netherlands and the EU in 2000 in all age groups

\begin{tabular}{lllll}
\hline & $\begin{array}{l}\text { Pharmo } \\
\text { area } \\
\text { (total) }\end{array}$ & $\begin{array}{l}\text { Pharmo area } \\
\text { (per 1000 } \\
\text { inhabitants) }\end{array}$ & $\begin{array}{l}\text { The } \\
\text { Netherlands } \\
\left(\times 10^{6}\right)\end{array}$ & $\begin{array}{l}\text { EU } \\
\left(\times 10^{6}\right)\end{array}$ \\
\hline $\begin{array}{l}\text { No. of } \\
\text { prescriptions }\end{array}$ & 250000 & 744 & 12.4 & 280 \\
$\begin{array}{l}\text { No. of users } \\
\begin{array}{l}\text { No. of } \\
\text { continuous }\end{array}\end{array}$ & 40800 & 121 & 2.0 & 46 \\
users & 13510 & 40 & 0.7 & 15 \\
\hline
\end{tabular}


Table III. Absolute numbers of continuous users and prevalence of any use of benzodiazepines in the Pharmo area in 2000 (age groups of 55 years and older).

\begin{tabular}{lcccccc}
\hline & \multicolumn{2}{l}{ Absolute number of continuous users } & \multicolumn{3}{l}{ Use per 1000 residents } \\
\cline { 2 - 7 } Age group (years) & women & men & total & women & men & all \\
\hline $55-59$ & 781 & 383 & 1164 & 90.7 & 43.1 & 66.6 \\
$60-64$ & 839 & 384 & 1223 & 116.4 & 54.5 & 85.7 \\
$65-69$ & 948 & 366 & 1314 & 141.4 & 62.2 & 103.9 \\
$70-74$ & 1035 & 384 & 1419 & 171.8 & 79.8 & 131.3 \\
$75-79$ & 1115 & 375 & 1490 & 205.4 & 104.8 & 165.7 \\
$80-84$ & 885 & 248 & 1133 & 252.5 & 132.8 & 212.0 \\
$85+$ & 824 & 209 & 1033 & 297.2 & 207.3 & 274.0 \\
All ages $\geq 55$ & 6427 & 2349 & 8776 & 159.7 & 71.0 & 119.7 \\
\hline
\end{tabular}

\section{Fall-Related Hospitalisation Costs in}

\section{The Netherlands}

The estimated admission costs for fall-related injuries in patients aged over 55 years are $€ 214$ million in 2000. Based on the calculated PARs from the study population, the cost of benzodiazepine injury-related admissions was assessed at $€ 48.5$ million (range $€ 39.0-58.8$ million), comprising $18.9 \%$ (95\% CI 15.2-22.9\%) of the total expenses in hospital-treated fall injuries in The Netherlands.

\section{Treatment Costs in the EU}

After adjustment for the varying hospitalisation costs in different countries, ${ }^{[16]}$ we estimated that over one million fall-related hospital admissions would lead to total hospitalisation costs of $€ 8.5$ billion in the EU. Most of this treatment cost was in the age group 55 years and older ( $>€ 7.8$ billion). Using the age-specific PARs, costs attributable to benzodiazepine use were estimated at approximately $€ 1.8$ billion ( $95 \% \mathrm{CI} € 1.5-2.2$ billion) in the $\mathrm{EU}$ (table IV) [year of valuation 2000 for all costs].

\section{Discussion}

The results of this study show that benzodiazepine use is an important risk factor for fall-related accidents among the elderly in the EU, resulting in total hospital treatment costs of between $€ 1.5-2.2$ billion in the EU. The actual economic consequences might even go beyond this amount, because only direct hospital costs were taken into account in this study. The large costs are explained by a high prevalence of benzodiazepine use among the elderly and high RRs in the older age groups.

The results of our case-control study are comparable with findings from previous studies. ${ }^{[1-3]}$ There were no differences found in risk rates according to the elimination half-life of benzodiazepines. In recent studies, the risk of accidental falls was largely explained by the prescribing of high doses of benzodiazepines to the elderly. ${ }^{[1,3]}$ Some studies suggested that an increased risk of falling

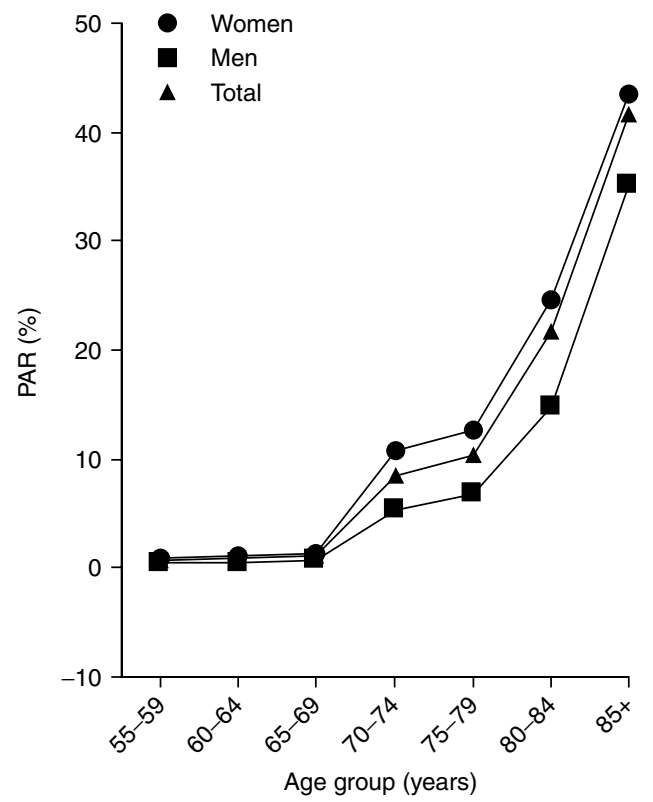

Fig. 1. Population attributive risk (PAR) of benzodiazepine fallrelated injuries based on the prevalence of the use of benzodiazepines per age stratum for men and women from the Pharmo study population. 
among the elderly was only associated with the use of long-acting benzodiazepines, not with short-acting. ${ }^{[18,19]}$ However, a meta-analysis of 40 observational studies indicated that there was no significant difference in the effect of short- and long-acting benzodiazepines. ${ }^{[3]}$ In a recent Dutch study, it was shown that in the past 5 years no changes were observed in the dosage of benzodiazepines given to the elderly, although guidelines recommend to prescribe half of the adult dosage of benzodiazepines to the elderly because of physiological and pharmacological reasons. ${ }^{[20]}$ In addition, they also found that the risk and, consequently, costs concentrate in a relatively small, but rapidly growing segment of the elderly population.

European estimates of the consequence of benzodiazepine use have hitherto been unknown because drug-use statistics are not consistently available for the individual members of the EU. In this study, we used statistics from IMS, an international company that obtains information on the use of pharmaceuticals worldwide, for the modelling of benzodiazepines for the different EU member countries. However, data of benzodiazepine use specified per country were incomplete, not available, not suitable or not affordable. Therefore, we assumed that the Dutch prevalence data of benzodiazepine use could be used as a proxy for benzodiazepine use in other European countries. These estimates are rather conservative and hence might result in an underestimation of the PAR, and, consequently, benzodiazepine fall-related treatment costs, as the lowest prescriptions per capita in Europe were in The Nether- lands. ${ }^{[21]}$ In addition, only hospitalisations were investigated as an outcome in this study. It may be assumed that the total costs of treatment of fallrelated accidental injuries attributable to benzodiazepine use are even more considerable. Moreover, the prevalence of benzodiazepine use and the incidence of falls may have changed in the past 3 years, because of aging of the Dutch population.

The same assumptions were made for the incidence of fall-related injuries, although it seems unreasonable to believe that the age- and gender-specific incidence differs much between countries in Europe. Based on findings of other authors, we considered the age- and gender-specific incidences of fall-related injuries in The Netherlands were on average at a level between the Scandinavian and Mediterranean countries. ${ }^{[22-24]}$ In addition, European discharge data on hip fractures per country were available to adjust for differences in fall injuryrelated admissions among countries. Another subject of discussion may be our assumption that hospitalisation costs in the EU were homogeneous. Although we corrected for differences in costs per country, it is possible that estimates for some countries might be overestimated, while other cost estimates might be underestimated. Comparison of our estimates of total hospital fall injury-related cost with the results of two European studies on osteoporotic fractures in Belgium and Austria, indicated that there was a 15-20\% overestimate of the Dutch costs. $^{[8,9]}$ Annual in-hospital expenses on osteoporotic fractures in the US were assessed at $€ 8.6$ billion $^{[6]}$ with the total injury-related cost in those

Table IV. Benzodiazepine (BZD)-associated costs (€ millions) for hospitalisations of BZD fall-related injuries by age group in the EU in 2000 based on relative risk (RR) and population attributable risk (PAR) data derived from the Pharmo study population (see also figure 1)

\begin{tabular}{lllllll}
\hline $\begin{array}{l}\text { Age } \\
\text { (years) }\end{array}$ & Population EU & $\begin{array}{l}\text { RR } \\
(95 \% \mathrm{Cl})\end{array}$ & $\begin{array}{l}\text { PAR \% } \\
(95 \% \mathrm{Cl})\end{array}$ & $\begin{array}{l}\text { No. of falls } \\
(\times 1000)\end{array}$ & $\begin{array}{l}\text { Total cost } \\
\text { BZD-related costs } \\
(95 \% \mathrm{Cl})\end{array}$ \\
\hline $55-59$ & 21181181 & $1.1(1.0-1.4)$ & $0.7(0.0-2.6)$ & 40.0 & 216 & $1.4(0.0-5.6)$ \\
$60-64$ & 20388651 & $1.1(1.0-1.4)$ & $0.9(0.0-3.3)$ & 46.1 & 304 & $2.6(0.0-10.1)$ \\
$65-69$ & 18097801 & $1.1(1.0-1.4)$ & $1.0(0.0-4.0)$ & 55.9 & 432 & $4.4(0.0-17.2)$ \\
$70-74$ & 16007168 & $1.7(1.5-2.0)$ & $8.4(6.2-11.6)$ & 83.2 & 845 & $71.1(52.0-98.0)$ \\
$75-79$ & 13122095 & $1.7(1.5-2.0)$ & $10.4(7.7-14.2)$ & 118.6 & 1407 & $146.2(107.6-199.9)$ \\
$80-84$ & 6704287 & $2.3(2.0-2.6)$ & $21.6(17.5-25.3)$ & 109.7 & 1488 & $321.4(260.2-376.8)$ \\
$85+$ & 7162816 & $3.6(2.9-4.5)$ & $41.6(34.2-48.9)$ & 214.7 & 3116 & $1296.2(1066.7-1525.2)$ \\
Total & 102663999 & & & 668.2 & 7808 & $1843.3(1486.5-2232.9)$ \\
\hline
\end{tabular}


aged 50 years possibly approximating $€ 13$ billion (1995 costs). In this perspective, our European findings appear to be modest.

Our sample size appeared adequate. Leipzig et al. ${ }^{[3]}$ indicated in their meta-analysis that the overall $\mathrm{RR}$ for benzodiazepine fall-related injuries is between 1.4 and 1.5. Our results show we are able to demonstrate similar RRs with our study group. We are also able to show significant results in the different age groups.

\section{Conclusion}

Our study gives insight into the magnitude of costs associated with benzodiazepine-related fall injuries at a European level. Although the confidence limits are wide, even the lower estimate points to their enormous economic consequence. This is especially alarming as the proportion of elderly in the EU grows rapidly. Moreover, there is clear evidence that a substantial part of these injuries can be avoided by refraining from prescribing high doses to the elderly. ${ }^{[1,25]}$ Concerted EU action is needed to convince prescribers and regulators to abstain from unnecessary prescribing of benzodiazepines.

\section{Acknowledgements}

We thank all pharmacists, medical specialists and staff members of the hospitals participating in the Pharmo system.

This study was supported by an unrestricted grant from Pfizer International, New York, USA.

\section{References}

1. Herings RM, Stricker BH, de Boer A, et al. Benzodiazepines and the risk of falling leading to femur fractures: dosage more important than elimination half-life. Arch Intern Med 1995; 155 (16): $1801-7$

2. Neutel CI, Perry S, Maxwell C. Medication use and risk of falls. Pharmacoepidemiol Drug Saf 2002; 11 (2): 97-104

3. Leipzig RM, Cumming RG, Tinetti ME. Drugs and falls in older people: a systematic review and meta-analysis: I. Psychotropoic drugs. J Am Geriatr Soc 1999; 47 (1): 30-9

4. Lindsay R. The burden of osteoporosis: cost. Am J Med 1995; 98 (2A): $9 \mathrm{~S}-11 \mathrm{~S}$

5. Dolan P, Torgerson DJ. The cost of treating osteoporotic fractures in the United Kingdom female population. Osteoporos Int 1998; 8 (6): 611-7

6. Ray NF, Chan JK, Thamer M, et al. Medical expenditures for the treatment of osteoporotic fractures in the United States in
1995: report from the National Osteoporosis Foundation. J Bone Miner Res 1997; 12 (1): 24-35

7. Johnell $\mathrm{O}$. The socioeconomic burden of fractures: today and in the 21st century. Am J Med 1997; 103 (2A): 20S-5S

8. Koeck CM, Schwappach DL, Niemann FM, et al. Incidence and costs of osteoporosis-associated hip fractures in Austria. Wien Klin Wochenschr 2001; 113 (10): 371-7

9. Reginster JY, Gillet P, Ben Sedrine W, et al. Direct costs of hip fractures in patients over 60 years of age in Belgium. Pharmacoeconomics 1999; 15 (5): 507-14

10. Herings RM, Klungel $\mathrm{OH}$. An epidemiological approach to assess the economic burden of NSAID-induced gastrointestinal events in The Netherlands. Pharmacoeconomics 2001; 19 (6): $655-65$

11. Coughlin SS, Benichou J, Weed DL. Attributable risk estimation in case-control studies. Epidemiol Rev 1994; 16 (1): 51-64

12. Herings RMC. PHARMO: a record linkage system for postmarketing surveillance of prescription drugs in The Netherlands [Doctorate]. Utrecht: Utrecht University, 1993

13. Paas GRA, Veenhuizen KCW. Onderzoek naar de betrouwbaarheid van de Landelijke Medische Registratie (LMR). Utrecht: Prismant, 2001

14. Mantel-Teeuwisse AK, Klungel OH, Verschuren WM, et al. Comparison of different methods to estimate prevalence of drug use by using pharmacy records. J Clin Epidemiol 2001; 54 (11): 1181-6

15. Miettinen OS. Theoretical epidemiology. Montreal: John Wiley \& Sons Inc, 1985

16. OECD. OECD Health Data 2001. Paris: OECD Paris Centre, 2001

17. Logistic regression examples using the SAS system. Version 6. Cary (NC), USA: SAS Institute Inc, 1995

18. Lord SR, Anstey KJ, Williams P, et al. Psychoactive medication use, sensori-motor function and falls in older women. Br J Clin Pharmacol 1995; 39 (3): 227-34

19. Ray WA, Griffin MR, Downey W. Benzodiazepines of long and short elimination half-life and the risk of hip fracture. JAMA 1989; 262 (23): 3303-7

20. Gorgels WJ, Oude Voshaar RC, Mol AJ, et al. [Long-term use of benzodiazepines]. Ned Tijdschr Geneeskd 2001; 145 (28): 1342-6

21. Bakker A. Drug use in the Netherlands, an introduction. In: Bakker A, Hekster YA, Leufkens HG, editors. Drug consumption in the Netherlands. Maarssen: Brocacef, 1991: 6-9

22. Boereboom FTJ, Raymakers JA, De Groot RRM, et al. Epidemiology of hip fractures in the Netherlands: women compared to men. Osteoporos Int 1992; 2: 279-84

23. Kannus P, Niemi S, Parkkari J, et al. Hip fractures in Finland between 1970 and 1997 and predictions for the future. Lancet 1999; 353 (9155): 802-5

24. Mazzuoli GF, Gennari C, Passeri M, et al. Hip fracture in Italy: epidemiology and preventive efficacy of bone-active drugs. Bone 1993; 14 Suppl. 1: S81-4

25. Beers MH. Explicit criteria for determining potentially inappropriate medication use by the elderly: an update. Arch Intern Med 1997; 157 (14): 1531-6

Correspondence and offprints: Dr Wim G. Goettsch, Pharmo Institute, PO Box 85222, Utrecht, $3508 \mathrm{AE}$, The Netherlands. E-mail: pharmo@pharmo.nl 